\title{
SISTEM INFORMASI GEOGRAFIS BERBASIS WEB PEMETAAN LOKASI TOKO OLEH-OLEH KHAS SAMARINDA
}

\author{
Adytama Annugerah $^{1)}$, Indah Fitri Astuti' ${ }^{2}$, Awang Harsa Kridalaksana ${ }^{3)}$ \\ ${ }^{1,2,3)}$ Program Studi Ilmu Komputer, Fakultas Ilmu Komputer dan Teknologi Informasi Universitas Mulawarman \\ Jalan Barong Tongkok Kampus Gunung Kelua Samarinda, Kalimantan Timur \\ Email : tamaadyt@gmail.com, indahfitriastuti@fmipa.unmul.ac.id, awangkid@gmail.com
}

\begin{abstract}
ABSTRAK
Sistem Informasi Geografis (SIG) atau Geographic Information System (GIS) merupakan sistem informasi berbasis komputer yang digunakan untuk mengolah dan menyimpan data atau informasi berbasis geografis. Penelitian ini bertujuan untuk menghasilkan sistem informasi geografis dengan visualisasi data spasial yang berisi letak toko oleh-oleh khas Samarinda, informasi toko dan petunjuk arah yang akan disajikan kepada user. Adapun data yang digunakan dalam penelitian ini adalah dengan pengumpulan data peta wilayah Kota Samarinda menggunakan Google Map API dan Google Map Direction Service, wawancara dengan pemilik toko, pengumpulan data titik koordinat serta beberapa data penunjang lainnya. Hasil dari penelitian ini adalah telah dibangun sebuah web sistem informasi geografi toko oleh-oleh khas Samarinda berbasis web menggunakan Google Maps API yang memberikan kemudahan kepada pengguna web untuk mengetahui posisi toko oleh-oleh Khas Samarinda, dimana didalamnya terdapat informasi toko, posisi toko, barang yang dijual dan petunjuk arah menuju toko yang diinginkan.
\end{abstract}

Kata kunci : Google map API, sistem informasi geografis, toko oleh-oleh.

\section{PENDAHULUAN}

Kota Samarinda memiliki toko-toko cinderamata atau oleh-oleh yang menjadi salah satu upaya untuk memperkenalkan hasil kerajinan yang ada di Samarinda. Bagi wisatawan yang mengunjungi Kota Samarinda atau yang melintasi Kota Samarinda, biasanya memiliki minat untuk membawa pulang sesuatu dari kota yang telah dikunjungi dimana oleh-oleh yang dimiliki Kota Samarinda terbilang cukup banyak. Oleh-oleh tersebut terdiri dari makanan dan barang-barang yang merupakan lambang dari Kota Samarinda yaitu, amplang, kain sarung samarinda dan masih banyak lagi makanan, pakaian dan pernak-pernik lainnya.

Dikarenakan pengetahuan yang terbatas terhadap letak toko-toko tersebut, masyarakat maupun wisatawan hanya mengunjungi toko yang mereka temui ketika berada dijalan dikarenakan letaknya yang strategis, sehingga toko-toko lain maupun toko-toko baru menjadi pilihan kedua untuk dikunjungi.

Hal tersebut yang membuat wisatawan dan pengunjung lainnya mengunjungi toko-toko yang mudah ditemui atau yang direkomendasikan oleh orang-orang sekitar, sehingga keberadaan toko-toko lain tidak diketahui. Meskipun toko-toko yang lain memiliki barang yang sama dan harga yang terjangkau, dan karena lokasi yang tidak diketahui masyarakat luas membuat toko tersebut jarang untuk dikunjungi. Berdasarkan alasan tersebut, penulis bermaksud membuat Sistem Informasi Geografis pemetaan lokasi toko oleh-oleh khas Samarinda. Sistem Informasi Geografi (SIG) ini diharap dapat membantu masyarakat maupun wisatawan yang akan mengunjungi toko oleh-oleh dapat mengetahui letak geografi serta informasi toko yang akan dikunjungi.

Penelitian SIG ini telah banyak dilakukan oleh peneliti lain, beberapa penelitian adalah penelitian SIG yang mencakup daerah Kota Samarinda dengan studi kasus yang berbeda-beda, seperti penelitian Sistem Informasi Geografis Bengkel Sepeda Motor di Samarinda Menggunakan Quantum Geographic Information System oleh (Mutakin, 2015). Serta penelitian Sistem Informasi Geografi Wilayah Kampus Universitas Mulawarman Menggunakan Google Maps API oleh (Rosdania, 2015).

Berdasarkan uraian latar belakang masalah yang telah dijelaskan, maka dapat diidentifikasikan permasalahan yang ditemui yaitu masyarakat domestik maupun wisatawan (user) belum banyak mengetahui letak lokasi toko oleh-oleh yang tersebar di Kota Samarinda, maka dibuat sebuah Sistem Informasi Geografis Pemetaan Toko Oleholeh Khas Samarinda. Sistem yang akan dibuat adalah sebagai salah satu pemetaan toko oleh-oleh yang berada di Kota Samarinda, dimana sistem yang dibuat akan menyajikan letak toko serta informasi toko. SIG dibuat dengan menggunakan informasi yang berasal dari pengolahan sejumlah data, yaitu data geografis atau data yang berkaitan dengan posisi obyek di permukaan bumi menggunakan Google Map API. Teknologi SIG ini mengintegrasikan operasi pengolahan data berbasis database, seperti pengambilan visualisasi melalui gambar-gambar petanya. SIG akan disajikan dalam bentuk aplikasi desktop yang berbasis web agar dapat diakses oleh masyarakat luas. 


\section{TINJAUAN PUSTAKA}

\section{a. Sistem Informasi Geografi (SIG)}

Sistem Informasi Geografis (SIG) atau Geographic Information System (GIS) merupakan sistem informasi berbasis komputer yang digunakan untuk mengolah dan menyimpan data atau informasi geografis (Aronoff, 1989). SIG merupakan alat yang bermanfaat untuk pengumpulan, penimbunan, pengambilan kembali data yang diinginkan dan penayangan data keruangan yang berasal dari kenyataan dunia (Barrough, 1986).

Secara umum pengertian SIG adalah Suatu komponen yang terdiri dari perangkat keras, perangkat lunak, sumberdaya manusia dan data yang bekerja bersama secara efektif untuk memasukan, menyimpan, memperbaiki, memperbaharui, mengelola, memanipulasi, mengintegrasikan, menganalisa dan menampilkan data dalam suatu informasi berbasis geografis".

SIG mempunyai kemampuan untuk menghubungkan berbagai data pada suatu titik tertentu di bumi, menggabungkannya, menganalisa dan akhirnya memetakan hasilnya. Data yang akan diolah pada SIG merupakan data spasial yaitu sebuah data yang berorientasi geografis dan merupakan lokasi yang memiliki sistem koordinat tertentu, sebagai dasar referensinya. Sehingga aplikasi SIG dapat menjawab beberapa pertanyaan seperti; lokasi, kondisi, trend, pola dan pemodelan. Kemampuan inilah yang membedakan SIG dari sistem informasi lainnya.

\section{b. Google Map API}

Menurut Tulach (2008), API atau Application Programming Interface bukan hanya satu set class dan method atau fungsi dan signature yang sederhana. Akan tetapi API, yang bertujuan utama untuk mengatasi "clueless" dalam membangun software yang berukuran besar, berawal dari sesuatu yang sederhana sampai ke yang kompleks dan merupakan perilaku komponen yang sulit dipahami. Secara sederhana dapat dipahami dengan membayangkan kekacauan yang akan timbul bila mengubah database atau skema $X M L$. Perubahan ini dapat dipermudah dengan bantuan $A P I$.

Beberapa sumber yang didapat, dapat disimpulkan bahwa API adalah sekumpulan perintah, fungsi, class dan protokol yang memungkinkan suatu software berhubungan dengan software lainnya. Tujuan dari API adalah untuk menghilangkan "clueless" dari sistem dengan cara membuat sebuah blok besar yang terdiri dari software di seluruh dunia dan menggunakan kembali perintah, fungsi, class atau protokol yang mereka atau API miliki. Dengan cara ini, programmer tidak perlu lagi membuang waktu untuk membuat dan menulis infrastruktur sehingga akan menghemat waktu kerja dan lebih efisien.

Google Map adalah layanan aplikasi dan teknologi peta berbasis web yang disediakan oleh
Google, temasuk di dalamnya website Google Map (http://maps.google.com), Google Ride Finder, Google Transit, dan peta yang dapat disisipkan pada website lain melalui Google Maps API. Saat ini Google Map adalah layanan pemetaan berbasis web yang populer, dapat menambahkan layanan Google Map ke website dengan menggunakan Google Maps API. Google Maps API dapat ditambahkan ke website kita menggunakan JavaScript. API tersebut menyediakan banyak fasilitas dan utilitas untuk memanipulasi peta dan menambahkan konten ke peta melalui berbagai layanan, memungkinkan user untuk membuat aplikasi peta yang kuat pada website yang akan dibuat. Pengetahuan yang diperlukan untuk mengembangkan Google Maps API adalah tentang HTML dan JavaScript, sedangkan peta sudah disediakan oleh Google. Cukup hanya dengan berkonsentrasi tentang data dan biarkan urusan peta ditangani oleh Google, sehingga dapat menghemat waktu. Pada Google Maps API adalah versi 3, JavaScript API mirip dengan versi sebelumnya. Versi 3 disesain lebih cepat, khususnya untuk browser mobile seperti Android dan iPhone.

\section{c. Google Map Direction}

Akses layanan Directions bersifat asinkron, karena Google Maps API perlu membuat panggilan ke server eksternal. Karena itu, Anda perlu meneruskan metode callback untuk dieksekusi setelah permintaan diselesaikan. Metode callback ini harus memproses hasil. Perhatikan, layanan Directions mungkin mengembalikan lebih dari satu kemungkinan rencana perjalanan sebagai sebuah larik routes [ ] yang terpisah.

Untuk menggunakan petunjuk arah di Google Maps JavaScript API, buat sebuah objek bertipe DirectionService,route() untuk memulai permintaan ke layanan Direction, berikan literal objek DirectionService yang berisi istilah input dan metode callback dieksekusi setelah menerima respon.

Secara default, layanan Directions menghitung rute melalui titik jalan yang diberikan dalam urutan tertentu. Secara opsional, Anda bisa meneruskan optimizeWaypoints: true dalam DirectionRequest untuk memungkinkan layanan Directions mengoptimalkan rute yang disediakan dengan menata ulang titik jalan dalam urutan yang lebih efisien. (Optimalisasi ini merupakan aplikasi dari Travelling Salesman Problem.) Semua titik jalan harus merupakan persinggahan untuk layanan Directions guna mengoptimalkan rutenya.

Jika anda memerintahkan layanan Directions untuk mengoptimalkan urutan titik jalan, maka urutannya akan dikembalikan dalam bidang waypoin_order dalam objek DirectionResult.

\section{d. Oleh-oleh}

Oleh-oleh sering disinonimkan dengan suvenir, buah tangan, atau cinderamata adalah sesuatu yang 
dibawa oleh seorang wisatawan ke rumahnya untuk mengenang daerah yang telah dikunjungi, terutama para wisatawan. Oleh-oleh adalah benda yang ukurannya relative kecil dan harganya tidak mahal, untuk dihadiahkan, disimpan atau dibeli sebagai kenang-kenangan akan tempat yang telah dikunjungi.

Dalam Bahasa Indonesia suvenir sering disebut dengan cendera mata, oleh-oleh, atau buah tangan. Oleh-oleh tidak selalu berhubungan erat dengan benda, bisa juga dihubungkan dengan hasil olahan makanan khas dari daerah tertentu atau daerah yang sedang dikunjungi. Untuk oleh-oleh makanan yang terkenal di Samarinda adalah makanan yang berasal dari olahan ikan tenggiri yang biasa disebut dengan amplang.

Adapun oleh-oleh khas Samarinda yang berupa olahan makanan yaitu amplang, abon ikan, olahan kue kering, olahan makanan dari durian dan lainlain. Olahan yang berupa pakaian yaitu kain sarung samarinda, kaos khas samarinda dan batik kalimantan. Olahan yang berupa pernak-pernik yaitu aksesoris manik-manik, gantungan kunci, dan aksesoris dayak.

\section{e. Kota Samarinda}

Kota Samarinda terletak didaerah khatulistiwa. Datar dan berbukit antara 10-200 meter diatas permukaan laut. Dengan luas wilayah $718 \mathrm{KM}^{2}$. Kota Samarinda berbatasan dengan Kabupaten Kutai Kartanegara disebelah barat, timur, selatan dan utara. Kota Samarinda beriklim tropis basah, hujan sepanjang tahun. Suhu udara antara 24-32C, dengan curah hujan rata-rata $162 \mathrm{~mm}$, dan kelembaban udara rata-rata $82,7 \%$.

Wilayah administrasi Kota Samarinda terdiri dari 10 Kecamatan dan 53 Kelurahan. Penduduk Kota Samarinda sampai bulan Agustus 2013 tercatat sebanyak 950.919 jiwa. Dengan laju pertumbuhan $3-4 \%$ per tahun, yang terdiri dari suku bangsa dengan pemeluk agama terbanyak Islam, disamping terdapat juga pemeluk agama Kristen, Hindu, Budha dan Konghucu. Penduduk Kota Samarinda sebagian besar bekerja di sektor perdagangan, hotel dan redtoran. Sektor lain yang dominan adalah industri (Bappeda, 2012).

Kota Samarinda dibentuk dan didirikan pada tanggal 21 Januari 1960, berdasarkan UU Darurat No. 3 Tahun 1953, Lembaran Negara No. 97 Tahun 1953 tentang Pembentukan daerah-daerah Tingkat II Kabupaten/kotamadya di Kalimantan Timur.

Semula Kodya Dati II Samarinda terbagi dalam 3 kecamatan, yaitu Kecamatan Samarinda Ulu, Samarinda Ilir dan Samarinda Seberang. Kemudian dengan SK Gubernur KepalaDaerah Tingkat I Provinsi Kalimantan Timur No. 18/SK/TH-Pem/1969 dan SK No. 55/THPem/SK/1969, terhitung sejak tanggal 1 Maret 1969, wilayah administratif Kodya Dati II Samarinda ditambah dengan 4 Kecamatan, yaitu Kecamatan Palaran, Sanga-Sanga, Muara Jawa dan
Samboja (luas sekitar $2.727 \mathrm{~km}^{2}$ ). Saat ini pembagian Kecamatan di Samarinda tidak termasuk Sanga-Sanga, Muara Jawa dan Samboja ketiganya masuk dalam Kutai Kartanegara. Setelah PP No. 38 Tahun 1996 terbit, wilayah administrasi Kodya Dati II Samarinda mengalami pemekaran, semula terdiri dari 4 kecamatan menjadi 6 Kecamatan.

Adapun 6 Kecamatan di Samarinda adalah :

1) Kecamatan Sungai Kunjang

2) Kecamatan Samarinda Ulu

3) Kecamatan Samarinda Utara

4) Kecamatan Samarinda Ilir

5) Kecamatan Samarinda Seberang

6) Kecamatan Palaran

Pemekaran Kecamatan kembali dilakukan seiring dengan pertumbuhan penduduk yang cukup pesat dan pelayanan masyarakat yang semakin meningkat. Kecamatan-kecamatan di Samarinda yang semula berjumlah 6 , kini dimekarkan menjadi 10 Kecamatan. 4 Kecamatan hasil pemekaran tersebut antara lain:

7) Kecamatan Samarinda Kota

8) Kecamatan Loa Janan Ilir

9) Kecamatan Sambutan

10) Kecamatan Sungai Pinang

\section{METODE PENELITIAN}

Penelitian dilakukan untuk memperoleh data dan informasi yang dibutuhkan, maka metode yang digunakan dalam proses pengumpulan data adalah:

1. Studi Literatur

Metode penelitian yang digunakan adalah metode kajian studi literatur dengan acuan dari buku antara lain Dasar Pemograman WEB dinamis menggunakan PHP, Konsep-konsep Dasar Sistem Informasi Geografis dan jurnal SIG yang berjudul Aplikasi Sistem Informasi Geografis untuk pemetaan pariwisata Kabupaten Gianyar, penulis Swastikayana.

2. Wawancara

Teknik wawancara yaitu, suatu metode pengumpulan data dengan melakukan tanya jawab sepihak yang dilakukan secara sistematis dan berlandaskan kepada tujuan penelitian, yaitu dengan melakukan wawancara kepada semua pemilik toko yang telah di tentukan.

3. Observasi

Penulis melakukan pengamatan langsung di Kota Samarinda untuk mengambil data yang dibutuhkan seperti titik koordinat, letak toko dan gambar toko.

\section{HASIL DAN PEMBAHASAN}

Sistem informasi geografis yang dibangun berbasis web, dimana terdapat 3 user yang dapat mengakses website yaitu:

1. Admin

2. Member (pemilik toko)

3. User biasa 
Admin, member, dan user akan mengunjungi halaman utama website ketika pertama kali mengakses url website SIG toko oleh-oleh khas Samarinda, dimana website menampilkan peta lokasi toko oleh-oleh dengan filter toko. Terdapat juga menu lain pada website seperti menu login, daftar toko, daftar barang dan contact us. Selain filter toko user juga dapat memilih peta dengan petunjuk arah untuk mendapatkan petunjuk arah menuju toko yang diinginkan, berikut tampilan halaman utama website dan peta dengan petunjuk arah:

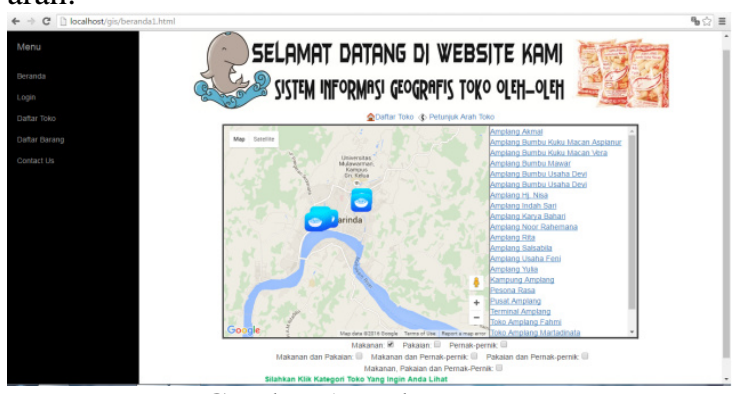

Gambar 1. Halaman Utama

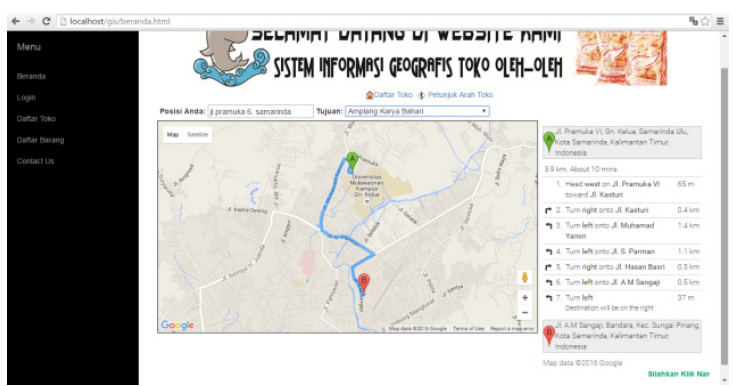

Gambar 2. Petunjuk Arah

Adapun gambar icon yang digunakan dalam menampilkan tiap-tiap toko berdasarkan kategori adalah sebagai berikut:

Tabel 1. Gambar Icon Toko

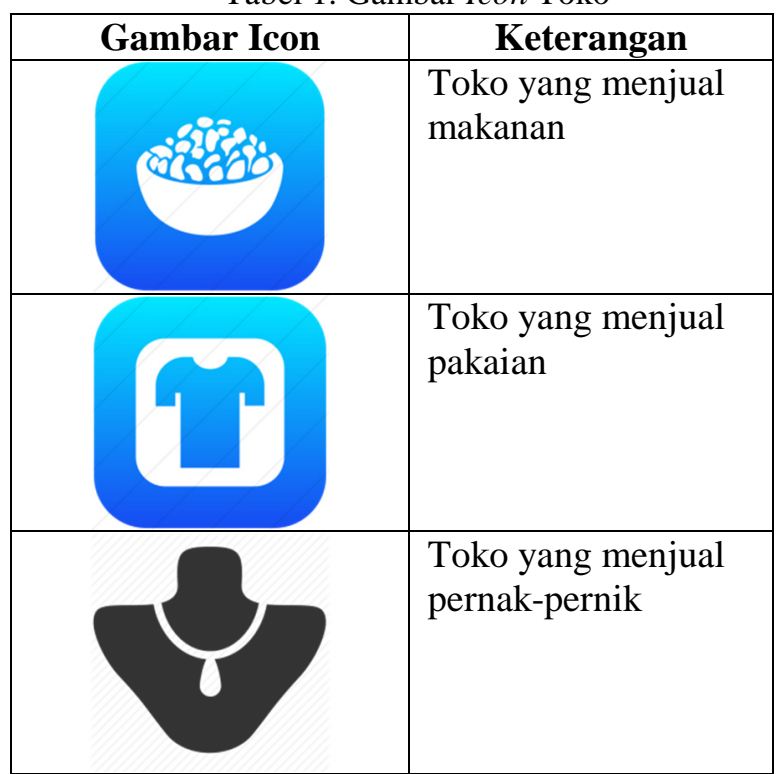

Hal pertama yang dilakukan admin dan member untuk masuk kedalam sistem yaitu mengunjungi halaman login agar admin dan member dapat memanipulasi data yang ada pada sistem, berikut tampilan halaman login admin dan member:

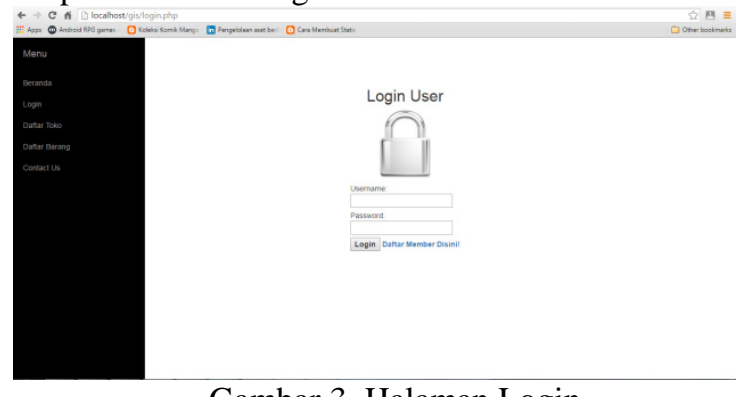

Gambar 3. Halaman Login

Setelah melakukan login admin dan member akan masuk kedalam sistem sistem dimana admin akan masuk kehalaman admin dan member akan masuk kehalaman member, berikut tampilan halaman admin dan member:

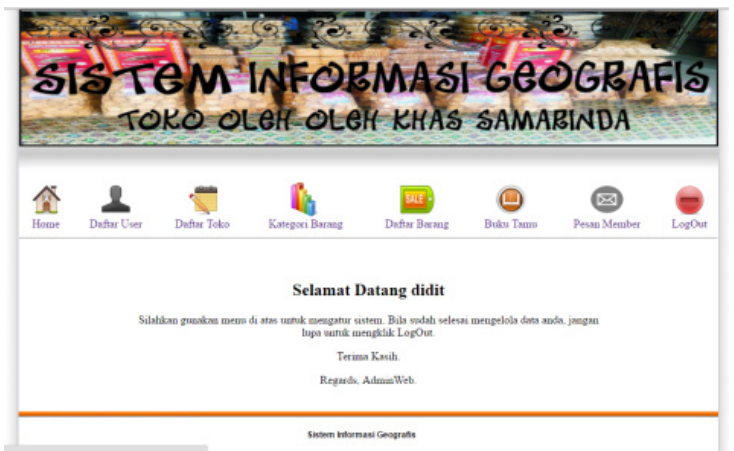

Gambar 4. Halaman Admin

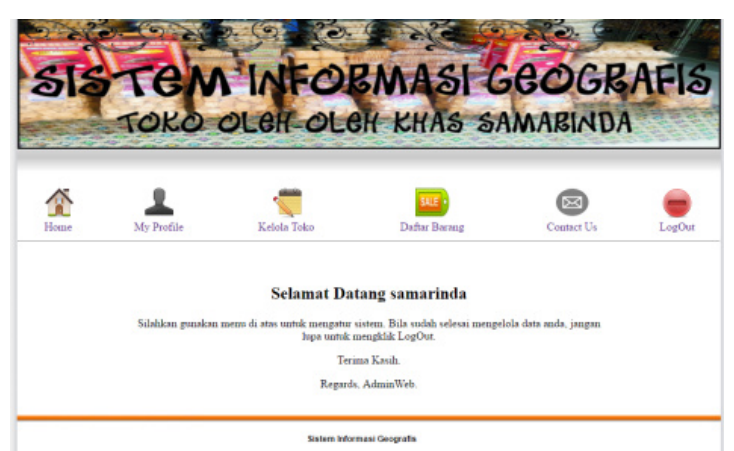

Gambar 5. Halaman Member

Perbedaan Halaman admin dan member ada pada menu sistem. User yang ingin mengakses website dapat melakukan registrasi agar mendapatkan akses sebagai member, berikut tampilan halaman registrasi:

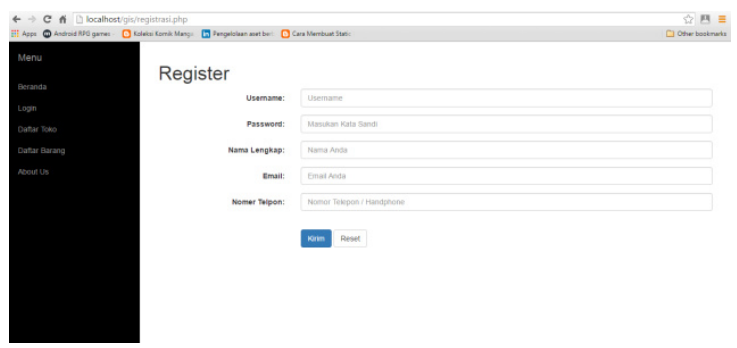

Gambar 6. Halaman Registrasi 
Admin dan member dapat menambah toko dan barang dengan mengakses menu yang ada, berikut tampilan daftar toko dan daftar barang:

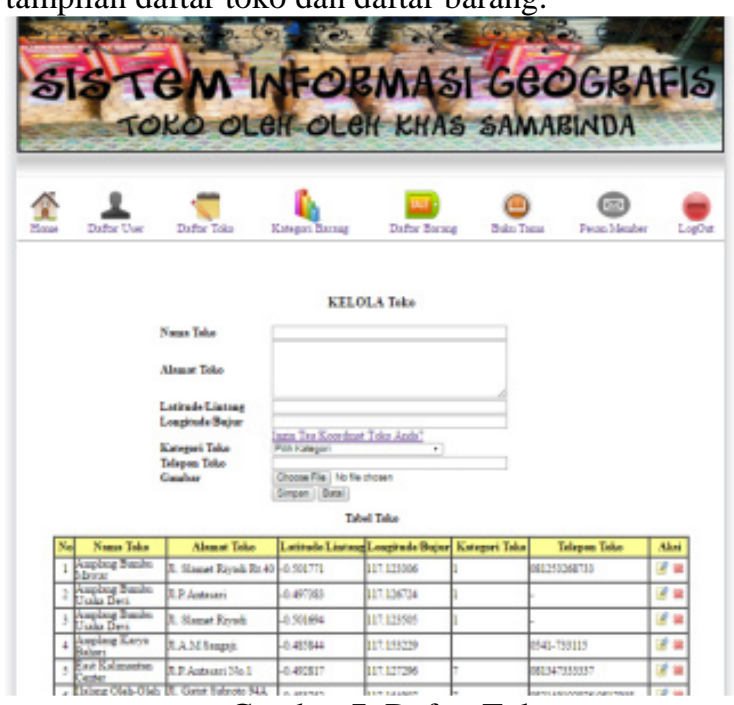

Gambar 7. Daftar Toko
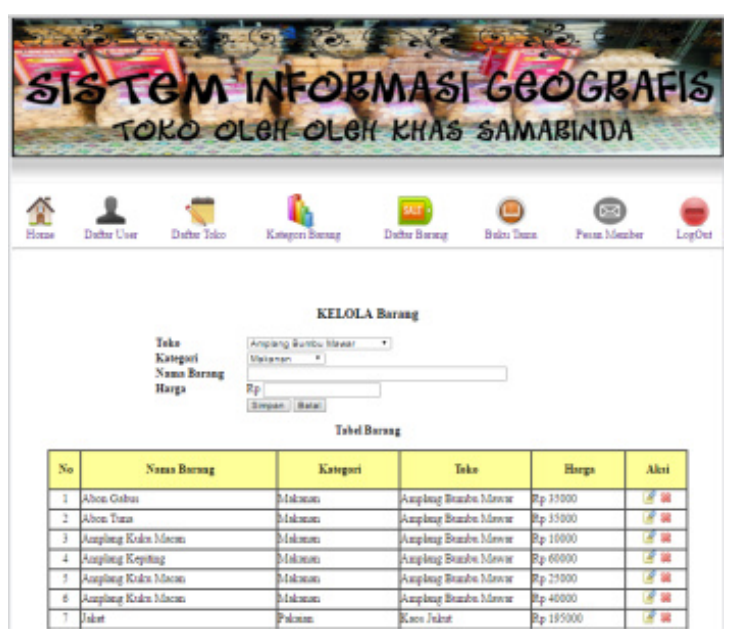

Gambar 8. Daftar Barang

Jika admin dan member tidak mengetahui koordinat lokasi tokonya, admin dan member dapat mengklik Ingin Tau Koordinat Toko Anda?, maka sistem akan menampilkan koordinat toko admin dan member dengan mengaktifkan gps yang ada pada web browsing. Berikut tampilan cari koordinat toko:

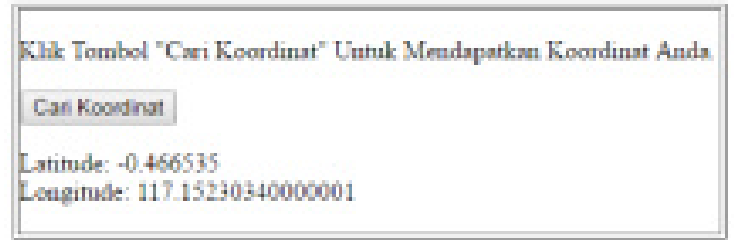

Gambar 9. Cari Koordinat

\section{KESIMPULAN}

Berdasarkan penelitian yang telah dilakukan oleh penulis, dapat diperoleh beberapa kesimpulan, diantaranya :

1. Telah dibangun sebuah web sistem informasi geografi toko oleh-oleh khas Samarinda berbasis web menggunakan Google Maps API.

2. Melalui web yang dibangun, memberikan kemudahan kepada pengguna web untuk mengetahui letak posisi toko oleh-oleh Khas Samarinda.

3. Berfungsi sebagai sebuah sistem informasi mengenai toko oleh-oleh khas Samarinda, dimana didalamnya terdapat informasi toko, posisi toko, barang yang dijual dan petunjuk arah menuju toko yang diinginkan.

\section{DAFTAR PUSTAKA}

[1]. Aronoff, S. 1989. "Geographic Information System a Management Perspective" (Terjemahan). WDL Publication, OttawaCanad

[2]. Barrough, 1986.Pengertian SIG dalam Dulbahri, 1993 tercantum di Laporan SIG Bengkel Sepeda Motor Menggunakan Quantum Geographic Information System Mutakin, 2015. Samarinda: Fakultas MIPA, Universitas Mulawarman

[3]. Mutakin, A.N. 2015. Judul Skripsi Sistem Informasi Geografi Bengkel Sepeda Motor Di Samarinda Menggunakan Quatum Geographic Information System. Samarinda: Universitas Mulawarman.

[4]. Rosdania. 2015. Judul Skripsi Sistem Informasi Geografi Wilayah Kampus Universitas Mulawarman Menggunakan Google Map API. Samarinda: Universitas Mulawarman.

[5]. Tulach, J. 2009. Practical API Design: Confessions of a Java Framework Architect. 